\title{
What has been the contribution of the first Global Fund grant (2003-2006) to malaria control and health system strengthening in Timor-Leste?
}

Joao Martins ${ }^{1,2^{*}}$, Anthony Zwi ${ }^{1}$, Paul Kelly ${ }^{3}$

From Parasite to Prevention: Advances in the understanding of malaria

Edinburgh, UK. 20-22 October 2010

\section{Background}

The Global Fund to fight against AIDS, Tuberculosis and Malaria was established in Geneva in January 2002 with the main objective of mobilizing resources from governments, donors, private sector and individuals to tackle HIV/AIDS, tuberculosis and malaria worldwide. Timor-Leste successfully obtained the first Global Fund grant with a value of nearly US \$3 million in 2003 for a three-year program for malaria control. The grant was aimed at reducing malaria-related morbidity and mortality by $30 \%$ by the end of the implementation. Necessary structures required by the Global Fund to allow grant implementation were established.

\section{Method}

A mixed methods approach was used to assess the impact of the grant implementation. The qualitative method employed in-depth interviews, group interviews,

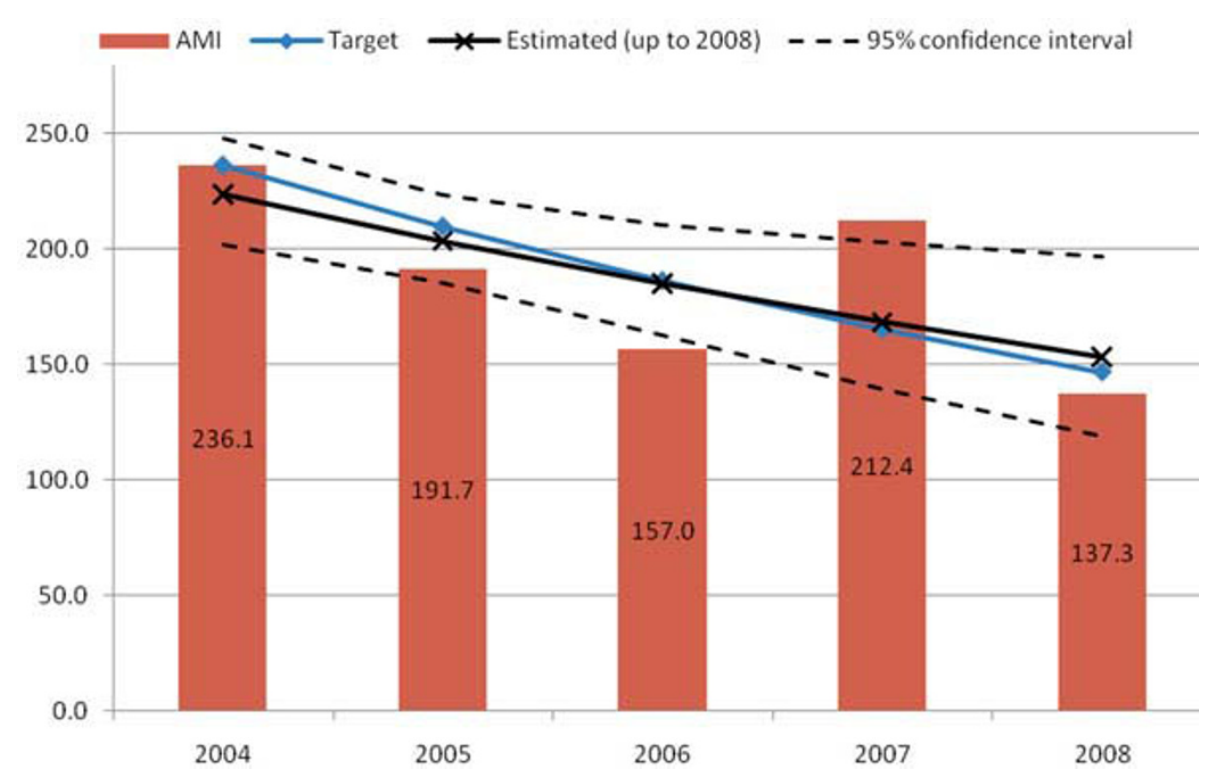

Figure 1 The AMI per 1000 in Timor-Leste 2004-2008.

${ }^{1}$ School of Public Health and Community Medicine, University of New South

Wales, Sydney, NSW, Australia, 2052

Full list of author information is available at the end of the article

(c) 2010 Martins et al; licensee BioMed Central Ltd. This is an open access article distributed under the terms of the Creative Commons Attribution License (http://creativecommons.org/licenses/by/2.0), which permits unrestricted use, distribution, and reproduction in any medium, provided the original work is properly cited. 
focus group discussions and observations. The quantitative method used the routinely collected morbidity data reported to the Ministry of Health.

\section{Results}

Timor-Leste with the Global Fund grant managed to reduce malaria morbidity by around $10 \%$ but did not achieve the stated objective (Figure 1). However, the Global Fund contributed considerably to malaria control program establishment, strengthening control interventions and the health system in general. It also brought direct benefits to pregnant women and the community at large. The implementation was hampered by inadequate human resources, the rigidity of Global Fund rules, weak project management and coordination, and lack of appropriate support.

\section{Conclusion}

Despite limitations, the grant was maintained until the agreed closing date. Considerable contributions to malaria control, health system and community have been made.

\section{Author details}

${ }^{1} S c h o o l$ of Public Health and Community Medicine, University of New South Wales, Sydney, NSW, Australia, 2052. ${ }^{2}$ Universidade da Paz, Dili, Timor-Leste.

${ }^{3}$ Australian National University, ACT, Canberra, Australia, 0200.

Published: 20 October 2010

\section{References}

1. Global Fund: Program grant agreement between the Global Fund to fight AIDS, Tuberculosis and Malaria and the Ministry of Health of the Government of the Democratic Republic of Timor-Leste. Geneva: The Global Fund to fight AIDS, Tuberculosis and Malaria 2003.

2. Global Fund: Annual Report 2002/2003. Geneva: The Global Fund to fight AIDS, Tuberculosisand Malaria 2003.

3. Martins JS, Zwi AB, Martins N, Kelly PM: Malaria control in Timor-Leste during a period of political instability: what lessons can be learned? Confl Health 2009, 3:11.

doi:10.1186/1475-2875-9-S2-023

Cite this article as: Martins et al:: What has been the contribution of the first Global Fund grant (2003-2006) to malaria control and health system strengthening in Timor-Leste? Malaria Journal 2010 9(Suppl 2):O23.

\section{Submit your next manuscript to BioMed Central} and take full advantage of:

- Convenient online submission

- Thorough peer review

- No space constraints or color figure charges

- Immediate publication on acceptance

- Inclusion in PubMed, CAS, Scopus and Google Scholar

- Research which is freely available for redistribution

Submit your manuscript at www.biomedcentral.com/submit 